\title{
Impaired motor function (clumsiness) in 5 year old children: correlation with neonatal ultrasound scans
}

\author{
Malcolm Levene, Sheila Dowling, Margaret Graham, Ken Fogelman, Maurice Galton, \\ Michael Phillips
}

\begin{abstract}
All 155 surviving children from a cohort of 200 very low birthweight infants originally studied in 1984-5 were traced. These infants had careful sequential ultrasound examinations in the neonatal period. The children were examined again at entry into school at 5 years of age. The test of motor impairment (TOMI) and the vocabulary subscale of the Wechsler preschool and primary scale of intelligence (WPPSI) were administered to 152 of the index cohort and 144 control children of the same age in the same class at school. Twelve of the cohort had cerebral palsy, but eight of these were in mainstream schools. The index group scored significantly higher on both the TOMI and the WPPSI subscale compared with the controls. The index cases were subdivided on the basis of their neonatal ultrasound scans into four groups: group 1, consistently normal; group 2, 'prolonged flare'; group 3, germinal matrix haemorrhageintraventricular haemorrhage (GMH-IVH), without parenchymal haemorrhage, but no evidence of prolonged flare; and group 4 , both GMH-IVH and prolonged flare. The group of index children with consistently normal ultrasound scans had a higher TOMI and lower WPPSI compared with their controls. There was a statistically significant increase in the TOMI subscore 1 (manual dexterity) in group 4 infants compared with group 1 , but not differences between the other groups. Regression analysis suggests that neither prolonged flare nor GMH-IVH has an important individual contribution to the variation, but the low birth weight does have a significant relationship with motor impairment. It appears that relatively minor ultrasound appearances such as prolonged flare and GMH-IVH are associated with motor impairment (clumsiness) at 5 years, but this has a small effect compared with low birth weight.
\end{abstract}

Cerebral palsy is the commonest serious neurological deficit occurring in babies who have been born very prematurely. A number of groups have reported an association between ultrasound abnormalities detected in the newborn period and subsequent cerebral palsy, ${ }^{1-3}$ particularly cystic periventricular leucomalacia $(\mathrm{PVL})^{1}$ and porencephaly. ${ }^{3}$ There is some suggestion that the ultrasound appearance we have previously defined as 'prolonged flare', but also referred to as 'small intraparenchymal echodensity', 'peritrigonal echogenic blush', and 'echogenic periventricular halo', may represent a less severe form of PVL.
We hypothesise that repeated assessment by real time ultrasound imaging detects a range of PVL injuries from severe (represented by multiple echofree cystic lesions) to moderate (prolonged flare or non-cavitating echodensity). It is probable that mild PVL will not be reliably detected on currently available imaging techniques. In 1984 and 1985 we prospectively collected a cohort of very low birthweight (VLBW) infants who had very careful and regular ultrasound scans performed throughout the neonatal period by a single ultrasonographer. ${ }^{4}$ Definitions of ultrasound abnormalities were agreed before the study and did not change through the 16 months of patient collection. We showed that cavitating PVL correlated well with the subsequent diagnosis of cerebral palsy ascertained at 18 months corrected for prematurity. ${ }^{1}$ In order to test our hypothesis that less severe ultrasound abnormalities may correlate with less severe degrees of motor impairment, we have examined the children from our 1984 cohort again at 5 years of age. We report here our findings relating to motor impairment at the age of 5 years. Reports of findings for other outcome variables are in preparation.

\section{Patients and methods}

Over a 16 month period from 1 January 1984, all VLBW infants $(<1501 \mathrm{~g})$ admitted to either the Leicester Royal Infirmary or the Nottingham City Hospital were regularly studied with real time ultrasound as previously described. ${ }^{4}$ Before undertaking the study, definitions of ultrasound abnormalities had been agreed and all the ultrasound scans were done at both hospitals by a single operator using an ATL ultrasound machine with a $7 \cdot 5 \mathrm{MHz}$ transducer at least twice weekly for the first month and then every week until discharge. All babies with ultrasound abnormalities on the scan before discharge were recalled for at least one further scan.

Early ultrasound abnormalities included germinal matrix haemorrhage-intraventricular haemorrhage (GMH-IVH), and parenchymal haemorrhage (an echodense area involving the ventricle and the parenchyma). Later changes (after two weeks from birth) were described as 'cystic periventricular leucomalacia' and prolonged flare (an appearance of relative increased echodensity in the periventricular region seen in both coronal and parasagittal views, and persisting for at least two weeks and not undergoing cystic degeneration). A porencephalic cavity was diagnosed if a large echofree area involving the parenchyma and in wide communication with the ipsilateral lateral ventricle was seen. This was always unilateral. 
Surviving children were examined by one neurodevelopmental paediatrician at 18 months (M Graham). ${ }^{1}$ The present study attempted to examine all these children again at 5 years of age in their first term in full time school. The head teacher of the school was contacted and asked for permission to assess the child in school. He or she was also asked to identify from the same class a control child of the same sex and ethnic background nearest in birth date to the index child. Written permission to assess the child was obtained from the parent(s). The head teacher was asked to tell the class teacher that these two children were to be assessed, but not the reason for the assessment, nor which child was the index case.

The two children were assessed separately but in the same session by one researcher (SD). The examination comprised: the test of motor impairment (TOMI), the vocabulary scale of the Wechsler preschool and primary scale of intelligence (WPPSI) and a number of measures of basic literacy, language, representational and mathematical concepts and skills most of which were used and reported by Tizard et al. ${ }^{8}$ Teachers were also asked to complete a checklist of behavioural statements. ${ }^{9}$

It was not possible to undertake complete neurological examinations on all the index and control children. The following children were examined by the same neurodevelopmental paediatrician who saw them at 18 months (M Graham): all children thought to be neurologically abnormal when seen at 18 months, including those who showed dystonia; all children with the ultrasound appearances of cystic PVL or prolonged flare in the neonatal period; and all children who had a high TOMI score above 10 , suggesting the possibility of definite neurological abnormality.

The TOMI originally described by Stott et al and revised by Henderson ${ }^{10}$ tests the child's level of skill in various motor functions. The test is arranged in four age bands, and the 5-6 year band was used in this study. The test has been recently standardised on a large number of British and North American children. The test involves eight items and for each item the child receives a score between 0 and 2: 0 denotes acceptable performance, 1 indicates borderline pass, and 2 indicates fail of that item. Thus the higher the score the less competent the child. The test includes three groups of items: manual dexterity, ball skills, and both static and dynamic balance. The maximum score for these three subscales were 6,4 , and 6 respectively. The TOMI normally took 20 minutes to administer, but could take up to 75 minutes if the child had particular difficulties. All but one of the TOMI assessments were done by the same observer. The entire assessment took an average of 75 minutes for each child.

For the purposes of this report only the TOMI and WPPSI variables are reported. Statistical analysis was done using the Wilcoxon or Mann-Whitney test on non-parametric data and by $t$ test for parametric (WPSSI) data. Regression analysis was performed using the square root of the total TOMI score in order to produce a regression equation with normal residuals.

\section{Results}

Of the original cohort of 200 infants, 157 were alive at 18 months and all but one (lost to follow up) had a complete neurodevelopmental assessment at that time. One further child died at three years (he had spastic hemiplegia) and all the 155 children alive at 5 years were traced. Three of these were not, however, fully assessed at 5 years. The parents of one refused to allow her to be seen, another lived in Cyprus and we could not organise assessment, and the third was in a vegetative state with spastic quadriplegia and profound intellectual impairment and could not be assessed with the TOMI; she was, however, examined by a developmental paediatrician (M Graham). Thus, 152 of the index children ( $97 \%$ of those seen at 18 months) had a full range of tests at 5 years. In some cases there were problems in identifying control children, for example they may have been absent from school when the visit was arranged, and only 144 controls were fully assessed.

Fifty of the 153 children had a neurological examination by a developmental paediatrician (M Graham). The indications for examination in this group were findings of either cerebral palsy $(n=11)$ or dystonia $(n=6)$ at 18 months, a neonatal ultrasound diagnosis of prolonged flare $(n=20)$, and cystic PVL in children who showed no neurological abnormality at 18 months $(n=5)$. In addition, eight other children were examined because they had a TOMI score over 10. In all, 12 of the index children had cerebral palsy (see table 1) and eight of these were in mainstream schools and four in special schools. Of the 12 children with cerebral palsy at 18 months, one had died, and one other no longer had signs of cerebral palsy at 5 years. The signs were largely unchanged in the other 10 . Two children with cerebral palsy at 5 years (No 26 and 179) did not show signs of it at 18 months. Neither of these had ultrasound abnormalities involving the cerebral parenchyma and both were reviewed because of a TOMI score above 10 .

The results of the TOMI assessments and the three subscores for all index and control children are shown in table 2 . The median TOMI in the index group of VLBW infant survivors was $3 \cdot 25$ (range 0-16) and the median figure for the controls was 1.00 (range $0-8$ ). The statistical comparison was made only between each index child and his/her control and 144 pairs were analysed. There was a highly statistically significant difference between the total TOMI score and each of the subscores $(\mathrm{p}<0.001)$. The mean (SD) WPPSI vocabulary scale for the index group was $19 \cdot 1(6 \cdot 41)$ and for the controls was $21 \cdot 6(6 \cdot 46)$. These differences were statistically significant $(p=0 \cdot 0007)$.

The index children were subdivided into four groups. Group 1 had consistently normal ultrasound scans $(n=64)$, group 2 had prolonged flare as the only ultrasound abnormality $(n=13)$, group 3 had GMH-IVH as the only ultrasound abnormality and no parenchymal involvement $(n=54)$, and group 4 infants had both prolonged flare and GMH-IVH without parenchymal involvement $(n=9)$. Children whose ultrasound scans had shown parenchymal haemorrhage or cystic PVL were excluded from this part of the 
Table 1 Details of the children with cerebral palsy diagnosed at 5 years

\begin{tabular}{|c|c|c|c|c|c|}
\hline Code No & $\begin{array}{l}\text { Birth weight } \\
(\mathrm{g})\end{array}$ & $\begin{array}{l}\text { Ultrasound } \\
\text { diagnoses }\end{array}$ & $\begin{array}{l}\text { Description } \\
\text { of cerebral palsy }\end{array}$ & $\begin{array}{l}\text { TOMI } \\
\text { score }\end{array}$ & $\begin{array}{l}\text { WPPSI } \\
\text { (vocabulary) }\end{array}$ \\
\hline 3 & 1300 & $\begin{array}{l}\text { Grade II PVH } \\
\text { and CPVL }\end{array}$ & Spastic quadriplegia* & 16 & 0 \\
\hline $\begin{array}{l}26 \\
42\end{array}$ & $\begin{array}{r}1400 \\
860\end{array}$ & $\begin{array}{l}\text { Normal } \\
\text { Grade II PVH } \\
\text { and CPVL }\end{array}$ & $\begin{array}{l}\text { Quadriplegia } \\
\text { Left hemiplegia }\end{array}$ & $\begin{array}{l}16 \\
9 \cdot 5\end{array}$ & $\begin{array}{r}0 \\
13\end{array}$ \\
\hline 81 & 1380 & $\begin{array}{l}\text { Grade III PVH } \\
\text { and CPVL }\end{array}$ & Left hemiplegia & 16 & $\mathbf{0}$ \\
\hline $\begin{array}{l}125 \\
126\end{array}$ & $\begin{array}{l}1190 \\
1180\end{array}$ & $\begin{array}{l}\text { Prolonged flare } \\
\text { Grade III PVH } \\
\text { and CPVL }\end{array}$ & $\begin{array}{l}\text { Left hemiplegia } \\
\text { Quadriplegia }\end{array}$ & $6 \cdot 5$ & 22 \\
\hline 130 & 1020 & $\begin{array}{l}\text { Grade III PVH, } \\
\text { prolonged flare }\end{array}$ & Right hemiplegia & $10 \cdot 5$ & 19 \\
\hline 132 & 1440 & $\begin{array}{c}\text { Grade II PVH } \\
\text { and CPVL }\end{array}$ & Diplegia, blind in one eye & 16 & 20 \\
\hline 157 & 1450 & $\begin{array}{c}\text { Grade II PVH } \\
\text { and CPVL }\end{array}$ & Left hemiplegia & 9 & 17 \\
\hline $\begin{array}{l}168 \\
177 \\
179\end{array}$ & $\begin{array}{r}830 \\
1500 \\
1250\end{array}$ & $\begin{array}{l}\text { Grade II PVH } \\
\text { CPVL } \\
\text { Grade I PVH }\end{array}$ & $\begin{array}{l}\text { Double hemiplegia } \\
\text { Diplegia } \\
\text { Diplegia }\end{array}$ & $\begin{array}{l}13 \\
11 \\
10\end{array}$ & $\begin{array}{l}14 \\
28 \\
19\end{array}$ \\
\hline
\end{tabular}

*This child was in a vegetative state and further assessment was not possible.

PVH, periventricular haemorrhage; CPVL, cystic periventricular leucomalacia.

analysis. Table 3 shows the overall TOMI and the subscores for each of these four groups. There was one child each in group 1 and 2 who had cerebral palsy. Two children in group 3 had cerebral palsy and none in group 4 . When the overall TOMI results were considered in the four groups there were no significant abnormalities. The children in group 4 had significantly higher scores for manual dexterity (subscale 1) than for those in group 1 with normal scans $(\mathrm{p}=0.033$, see table 3$)$. The WPPSI vocabulary scales showed no statistical differences when these groups were compared (group $1 v$ group 2, $\mathrm{p}=0.27$; group $1 v$ group $3, \mathrm{p}=0.88$ ). When children in group 1 (consistently normal ultra-

Table 2 Median (ranges) for TOMI and TOMI subscores and mean (SD) for the vocabulary scale of the WPPSI

\begin{tabular}{|c|c|c|c|c|c|}
\hline & \multicolumn{4}{|l|}{ TOMI } & \multirow{2}{*}{$\begin{array}{l}\text { WPPSI } \\
\text { (vocabulary) }\end{array}$} \\
\hline & Overall & $\underset{l}{\text { Subscore }}$ & ${ }_{2}^{\text {Subscore }}$ & ${ }_{3}^{\text {Subscore }}$ & \\
\hline $\begin{array}{l}\text { Index cases } \\
(n=152) \\
\text { Control cases } \\
(n=144) \\
p \begin{array}{l}\text { Values for } \\
\text { cases } v \text { controls }\end{array}\end{array}$ & $\begin{array}{l}3 \cdot 25 \\
(0-16) \\
1 \cdot 0 \\
(0-8) \\
<0.001\end{array}$ & $\begin{array}{l}1.0 \\
(0-6) \\
0.0 \\
(0-3.5) \\
<0.001\end{array}$ & $\begin{array}{l}1 \cdot 0 \\
(0-4) \\
0 \cdot 0 \\
(0-3) \\
<0.001\end{array}$ & $\begin{array}{l}1 \cdot 0 \\
(0-6) \\
0.0 \\
(0-5) \\
<0.001\end{array}$ & $\begin{array}{l}19 \cdot 1 \\
(S D 6.41) \\
21.6 \\
(S D 6.46) \\
0.0007^{*}\end{array}$ \\
\hline
\end{tabular}

The $\mathrm{p}$ values refer to one sample non-parametric Wilcoxon test and "paired Student's $t$ test. Subscore 1, manual dexterity; subscore 2, ball skills; subscore 3, static and dynamic balance

Table 3 Median (ranges) for TOMI and TOMI subscores and mean (SD) for the vocabulary scale of the WPPSI

\begin{tabular}{|c|c|c|c|c|c|}
\hline & \multicolumn{4}{|l|}{ TOMI } & \multirow{2}{*}{$\begin{array}{l}\text { WPPSI } \\
\text { (vocabulary) }\end{array}$} \\
\hline & Overall & $\underset{l}{\text { Subscore }}$ & ${ }_{2}^{\text {Subscore }}$ & ${ }_{3}^{\text {Subscore }}$ & \\
\hline $\begin{array}{l}\text { Group } 1(n=64) \\
\text { (no ultrasound } \\
\text { abnormality) }\end{array}$ & $\begin{array}{l}2 \cdot 25 \\
(0-16)\end{array}$ & $\begin{array}{l}0.5 \\
(0-6)\end{array}$ & $\begin{array}{l}1 \\
(0-4)\end{array}$ & $\begin{array}{l}1 \\
(0-6)\end{array}$ & $\begin{array}{l}19 \cdot 3 \\
(5 \cdot 82)\end{array}$ \\
\hline $\begin{array}{l}\text { Group } 2(n=13) \\
\text { (prolonged flare, PF) } \\
\text { Group } 3(n=54) \\
\text { (GMH-IVH) } \\
\text { Group } 4(n=9) \\
\text { (PF and GMH-IVH) } \\
\text { Statistical comparisons: }\end{array}$ & $\begin{array}{l}4 \cdot 5 \\
(0 \cdot 5-9 \cdot 5) \\
3 \\
(0-13) \\
5 \cdot 5 \\
(1-13)\end{array}$ & $\begin{array}{l}0 \cdot 5 \\
(0-5 \cdot 5) \\
1 \\
(0-5) \\
1 \cdot 5 \\
(1-4)\end{array}$ & $\begin{array}{l}1 \\
(0-2) \\
1 \\
(0-3) \\
1 \\
(0-4)\end{array}$ & $\begin{array}{l}2 \\
(0-5) \\
1 \\
(0-6) \\
2 \\
(0-6)\end{array}$ & $\begin{array}{l}21 \cdot 1 \\
(4 \cdot 91) \\
19 \cdot 2 \\
(6 \cdot 64) \\
18 \cdot 6 \\
(7 \cdot 68)\end{array}$ \\
\hline 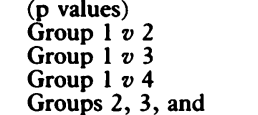 & $\begin{array}{l}0 \cdot 237 \\
0 \cdot 260 \\
0 \cdot 061\end{array}$ & $\begin{array}{l}0.411 \\
0.429 \\
0.033\end{array}$ & $\begin{array}{l}0 \cdot 840 \\
0 \cdot 930 \\
0 \cdot 110\end{array}$ & $\begin{array}{l}0 \cdot 156 \\
0 \cdot 184 \\
0 \cdot 460\end{array}$ & $\begin{array}{l}0 \cdot 27 \\
0 \cdot 88 \\
0 \cdot 78\end{array}$ \\
\hline $4 v 1$ & 0.088 & $0 \cdot 162$ & 0.595 & 0.098 & 0.94 \\
\hline
\end{tabular}

The $\mathrm{p}$ values refer to two sample non-parametric Mann-Whitney tests and two sample Student's $t$ test for the WPPSI data. sound scans) were compared with their controls and for the total TOMI score there was a estimated difference (case minus control) of 1.5 $(\mathrm{p}<0.001$ non-parametric Wilcoxon signed rank test); and when compared for the WPPSI (vocabulary scale) an estimated difference (case minus control) of $-3.0(p=0.015)$.

Regression analysis was initially undertaken using GMH-IVH and prolonged flare as independent variables against the square root of total TOMI score as the dependent variable. This gave a $t$ ratio for the coefficient of prolonged flare of $1 \cdot 82(p=0 \cdot 07)$ and for GMHIVH of $1 \cdot 14(p>0 \cdot 1)$. When birth weight was added to the model as a third independent variable, the $t$ ratio for prolonged flare fell to $1.68(p=0.1)$ and the estimate of the coefficient of birth weight was negative with a value of -1.04 (SE 0.36, $t$ ratio $-2 \cdot 89, \mathrm{p}=0.005$ ). Birth weight accounted for the greatest proportion of the variation explained by the regression equation.

\section{Discussion}

It is well known that cerebral palsy is approximately 200 times more likely to occur in children who have been born very prematurely than in a group of babies born at full term. It has also been reported that children who have been born very prematurely and who show no 'hard' neurological deficits, may perform less than optimally when they start school due to a number of factors. These include behavioural problems, ${ }^{11}$ attention deficit disorders, ${ }^{12}$ and a group of non-specific problems referred to as 'soft neurological signs'"13 or 'minimal brain dysfunction'.14

We have shown that there are important differences in both motor function and measures of verbal intelligence between children who were of very low birth weight and controls when assessed at 5 years. These findings are in keeping with those of Marlow et al who assessed 53 children at 6 years who weighed less than $1251 \mathrm{~g}$ at birth. ${ }^{15}$ They also used the TOMI to detect significant motor difficulties. The TOMI is now a well accepted objective diagnostic test for clumsiness. We may be criticised for only 
using the vocabulary subscale of the WPPSI test, but we were concerned that a fuller assessment of intelligence, together with all the other components of our assessment would fatigue the children. We chose a subscale of intelligence that was not motor dependent. Astbury et al have shown that in a group of VLBW survivors assessed at 5 years the verbal subscore of the WPPSI correlated very well with the mean performance score and the full scale score. ${ }^{12}$

This study has correlated relatively subtle ultrasound abnormalities with motor impairment at 5 years. We have shown a statistically significant relationship between the scan appearances of both GMH-IVH with prolonged flare and subsequent impairment of manual dexterity. There is some correlation between the appearance of non-cavitating echodensity (defined by various authors in different ways ${ }^{4-7}$ ) and necropsy specimens, suggesting that this appearance is $70-81 \%$ accurate for PVL. ${ }^{6}{ }^{16} \mathrm{It}$ is now well accepted that cavitating abnormalities within the cerebral parenchyma recognised with ultrasound imaging correlate with the development of cerebral palsy, ${ }^{1-3}$ but there are no data on the more subtle ultrasound abnormalities and less severe forms of central motor impairment. We have previously shown that cystic PVL diagnosed by ultrasound strongly correlated with the subsequent development of cerebral palsy, ${ }^{1}$ but this most recent report adds little weight to the hypothesis we had previously suggested that prolonged flare represented a less severe form of injury to the periventricular white matter. It will be necessary to follow up much larger groups of premature infants with the appearances of prolonged flare to know whether this feature is actually a marker of subsequent development of clumsiness. We only compared children with no evidence of major parenchymal abnormality to avoid the possibility that these lesions are likely to have a very large effect on the overall TOMI score, thus swamping more subtle effects of 'minor' ultrasound scan abnormalities.

It is unfortunate that not all the VLBW infants had a neurological assessment at 5 years, but this was not logistically possible given the budget of this project. In all, one third of the index children were examined. It is of interest that one child found to have cerebral palsy at 18 months neither showed abnormal neurological signs at 5 years, nor did she have a high TOMI score. Two children who were thought to be normal at 18 months were found to have cerebral palsy on neurological assessment. Both these were undiagnosed by their medical attendants and were picked up by a very high TOMI score.

One of the most interesting findings in this study, and one that has not been reported before, is that those children who had been born of VLBW and who had consistently normal ultrasound scans had significantly higher TOMI and lower WPPSI (vocabulary) scores compared with controls. It is possible that ultrasound invisible haemorrhagic or ischaemic lesions were present but were not severe enough to account for these deficits. We believe that this is somewhat less likely than an alternative hypothesis that there was neuronal loss as the result of other factors such as undernutrition, ${ }^{17}$ subclinical hypoglycaemia, ${ }^{18}$ or lack of early learning opportunities. These variables deserve further investigation.

Wariyar et al have criticised follow up studies that have failed to study all children in a cohort and they showed that those children who were most difficult to find were the ones who were most likely to have significant disability. ${ }^{19} \mathrm{We}$ identified $99.5 \%$ of all the children known to be alive at 18 months of age and examined all but two of these. It is unlikely that results from the two missing children would significantly alter our conclusions.

In summary, we report the association between the ultrasound appearance of GMH-IVH and prolonged flare on the one hand and motor impairment or clumsiness on the other. This association is very dependent on low birth weight; it appears that the risk of motor impairment is most closely related to increasingly low birth weight. The motor impairment may cause significant difficulties at school and may be a feature of later learning problems. ${ }^{20}$

We are very grateful to Action Research for the Cripped Child for financial support of this project and to all the schools and parents who cooperated with us. The high response rate owes much to the organisational skills and tactful perseverance of Julia Thomson.

1 Graham M, Levene MI, Trounce JQ, Rutter N. Prediction of cerebral palsy in very low birthweight infants: prospective ultrasound study. Lancet 1987;ii:593-6.

2 Stewart AL, Reynolds EOR, Hope PL, et al. Probability of neurodevelopmental disorders estimated from ultrasound appearance of brains of very preterm infants. Dev Med Child Neurol 1987;29:3-11.

3 Cooke RWI. Early and late cranial ultrasonographic appearances and outcome in very low birthweight infants. Arch Dis Child 1987;62:931-7.

4 Trounce JQ, Rutter N, Levene MI. Periventricular leukomalacia and intraventricular haemorrhage in the preterm neonate. Arch Dis Child 1986;61:1196-202.

5 McMenamin JB, Shackelford GD, Volpe JJ. Outcome of neonatal intraventricular hemorrhage with periventricular echodense lesions. Ann Neurol 1984;15:285-90.

6 DiPietro MA, Brody BA, Teele RL. Peritrigonal echogenic 'blush' on cranial sonography: pathologic correlates. $A \mathcal{Y} R$ 1986;146:1067-72.

7 Grant EG, Schellinger D, Richardson JD, Coffey ML, Smirniotopoulous JG. Echogenic periventricular halo: normal sonographic finding or neonatal cerebral haemorrhage. $A \mathcal{F} R$ 1983;140:793-6.

8 Tizard B, Blatchford $\mathrm{P}$, Burke J, et al. Young children in the inner city. London: Lawrence Erlbaum, 1988.

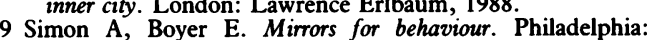
Research for Better Schools, 1967.
.

10 Stott DH, Moyes FA, Henderson SE. Test of motor impairment. Revised by Henderson SE. Guelph: Brook Educational, 1984.

11 McCormick MC, Gortmaker SL, Sobol AM. Very low birth weight children: behavior problems and school difficulty in a national sample. F Pediatr 1990;117:687-93.

12 Astbury J, Orgill A, Bajuk B. Relationship between two-year behaviour and neurodevelopmental outcome at five years of very low-birthweight survivors. Dev Med Child Neurol 1987;29:370-9.

13 Hertzig ME. Neurological 'soft' signs in low-birthweight children. Dev Med Child Neurol 1981;23:778-91

14 Dunn HG, ed. Sequelae of low birthweight: the Vancouver study. London: MacKeith Press, 1986.

15 Marlow N, Roberts BL, Cooke RWI. Motor skills in extremely low birthweight children at the age of 6 years. Arch Dis Child 1989;64:839-47.

16 Trounce JQ, Fagan D, Levene MI. Intraventricular haemorrhage and periventricular leucomalacia: ultrasound and autopsy correlation. Arch Dis Child 1986;61:1203-7.

17 Lucas A, Morley R, Cole TJ, et al. Early diet in preterm babies and developmental status at 18 months. Lancet 1990;335:1477-81.

18 Anonymous. Brain damage by neonatal hypoglycaemia [Editorial]. Lancet 1989; ;:882-3.

19 Wariyar U, Richmond S, Hey E. Pregnancy outcome at 24-31 weeks' gestation: neonatal survivors. Arch Dis Child 1989;64:678-86.

20 MacKinlay I, England A, Nash S, et al. The predictive value of coordination testing. Neuropaediatrics 1981;12(Suppl): 426. 